Pesq. Vet. Bras. 37(12):1483-1490, dezembro 2017 DOI: $10.1590 / \mathrm{S} 0100-736 \mathrm{X} 2017001200020$

\title{
Deep tissue culture and hemoculture in dogs with wounds and sepsis ${ }^{1}$
}

\author{
Mônica V. Bahr Arias ${ }^{2 *}$, Flávia N. Padilha ${ }^{3}$ and Marcia R.E. Perugini ${ }^{4}$
}

\begin{abstract}
Bahr Arias M.V., Padilha F.N. \& Perugini M.R.E. 2017. Deep tissue culture and hemoculture in dogs with wounds and sepsis. Pesquisa Veterinária Brasileira 37(12):14831490. Departamento de Clínicas Veterinárias, Universidade Estadual de Londrina, Rodovia Celso Garcia Cid Km 380, Londrina, PR 86057-970, Brazil. E-mail: vicky@uel.br

Contaminated and infected wounds occur very frequently in veterinary medicine and can cause systemic inflammatory response syndrome, sepsis, and death. This study aimed to test the feasibility of collecting wound material by deep-tissue or punch biopsy for microbial culture, determine the frequency of bacteria in the wound(s) and blood cultures and the susceptibility of these microbes to antimicrobials, and evaluate clinical parameters that could be related to prognosis. Thirty dogs with wounds and signs of SIRS/sepsis were included in this study. Bacteria were isolated from all wounds and 41 bacterial isolates could be identified based on culture of the materials collected by punch biopsy; $53.66 \%$ of the isolates were gram-negative, mainly involving Pseudomonas aeruginosa, Klebsiella pneumoniae, and Enterococcus spp., and $46.34 \%$ were gram-positive bacteria such as Streptococcus spp., Enterococcus spp., and Staphylococcus spp. The survival rate was $66.67 \%$. Based on blood culture analysis, we identified bacteremia in seven patients, predominantly of gram-negative bacteria, which negatively affected patient survival, as six dogs died. Hypoglycemia $(\leq 60 \mathrm{mg} / \mathrm{dL})$ and severe hyperglycemia $(\geq 180 \mathrm{mg} / \mathrm{dL})$ also negatively affected survival as $23.33 \%$ of the hypo/hyperglycemic dogs died. Factors such as blood lactate level at admission and hematocrit levels, and mean arterial pressure were not significantly correlated with death or survival of the dogs.
\end{abstract}

INDEX TERMS: Tissue culture, hemoculture, dogs, sepsis, bacteria, bacteremia, blood glucose.

RESUMO.- [Cultura de tecido profundo e hemocultura em cães com feridas e sepse.] As feridas contaminadas e infectadas em cães ocorrem com grande frequência na medicina veterinária e podem causar síndrome da resposta inflamatória sistêmica, sepse e morte. Os objetivos do presente trabalho foram verificar a viabilidade da técnica de coleta de material da ferida por biópsia para realização de cultura microbiana, determinar a frequência das bactérias nas culturas das feridas e hemoculturas e a susceptibilidade destes agentes aos antimicrobianos, bem como avaliar

\footnotetext{
${ }^{1}$ Received on January 18, 2016.

Accepted for publication on April 6, 2017.

${ }^{2}$ Departamento de Clínicas Veterinárias, Universidade Estadual de Londrina (UEL), Rodovia Celso Garcia Cid Km 380, Londrina, PR 86057-970, Brazil.*Autor para correspondência: vicky@uel.br

${ }^{3}$ Universidade Norte do Paraná (Unopar), Unidade Arapongas, PR 218 Km 1, Jd. Universitário, PR 86702-067, Brazil.

${ }^{4}$ Laboratório de Microbiologia Clínica, Departamento de Patologia, Análises Clínicas e Toxicológicas, Centro de Ciências da Saúde, Av. Robert Koch 60, Londrina, PR 86038-350, Brazil.
}

parâmetros clínicos que pudessem ser relacionados ao prognóstico em 30 cães com feridas e sinais de SIRS/sepse. Foram isoladas bactérias de todas as feridas e a técnica de coleta de material para cultura por biópsia permitiu a obtenção de 41 agentes microbianos, sendo isoladas 53,66\% bactérias Gram negativas e 46,34\% Gram positivas, principalmente Pseudomonas aeruginosa, Klebsiella pneumoniae e Enterococcus spp. As bactérias gram positivas isoladas foram Streptococcus spp., Enterococcus spp. e Staphylococcus spp. A taxa de sobrevivência foi $66,67 \%$. Na hemocultura constatou-se bacteremia em sete pacientes, com predominância de bactérias Gram negativas, o que influenciou negativamente na sobrevivência dos pacientes, pois seis cães vieram a óbito. A hipoglicemia $(\leq 60 \mathrm{mg} / \mathrm{dL})$ ou hiperglicemia severa $(\geq 180 \mathrm{mg} / \mathrm{dL}$ ), também influenciaram negativamente a sobrevivência, pois $23,33 \%$ dos pacientes hipo/ hiperglicêmicos vieram a óbito. Já fatores como nível sérico de lactato na admissão do paciente, pressão arterial média (PAM) e hematócrito não apresentaram correlação estatística com o óbito ou sobrevivência destes pacientes. 
TERMOS DE INDEXAÇÃO: Cultura de tecido, hemocultura, cães, sepse, bactérias, bacteriemia, glicemia.

\section{INTRODUCTION}

Contaminated and infected wounds occur very frequently in veterinary medicine (Arias et al. 2008). Factors such as type, quantity, and virulence of microorganisms and patient-linked aspects such as age, immunosuppression, and concomitant diseases influence the wound healing. Characteristics of bacteria that colonize and infect wounds, as pathogenicity and pattern of susceptibility to antimicrobials, can be affected by the wound care and use of topical and systemic antimicrobials. There are wounds which are not infected initially but have the potential to become so. Proper care of patient and antibiotic therapy may have good results, however the opposite also occurs, as overuse or misuse of antibiotics can result in development of antibiotic-resistant bacteria (Hedlund 2007).

Systemic inflammatory response syndrome (SIRS) is the clinical manifestation of the inflammatory response that occurs in response to an infectious or non-infectious insult to the animal as burns, trauma, heatstroke, pancreatitis ot immune-mediated disease (Gebhardt et al. 2009). Patients with wounds have a significant risk of developing secondary complications, because severe tissue trauma, with or without the presence of infections can initiate SIRS. The term sepsis is used in SIRS patients with concomitant infection (Gebhardt et al. 2009). Bacteriological confirmation of systemic infection by blood culture can be difficult, although negative results of the cultures do not rule out the presence of infection (Calvert \& Thomason 2011).

According to Amalsadvala \& Swaim (2006), different microorganisms can coexist in a wound; thus, it is important to differentiate the agents found on the wound surface from those actually responsible for infectious complications. In human medicine, identification of bacteria present in the wounds based on collecting wound fragments by biopsy is considered the gold standard (Bowler et al. 2001), as it provides precise information about the bacteria responsible for infections, especially in wounds covered by necrotic tissue (Steer 1996).

The aims of this study were to verify in dogs with contaminated and infected wounds the feasibility of collecting wound fragments by skin punch biopsy, the bacteria present in wounds and in positive blood cultures and antimicrobial susceptibility of these bacteria. Further, the epidemiologic data and hematocrit levels, blood glucose and lactate concentration were evaluated.

\section{MATERIALS AND METHODS}

The study was performed at the inpatient section of the Companion Animal Surgical Service at the Veterinary Hospital from Universidade Estadual de Londrina (HV/UEL), between April 2012 and January 2013. Thirty dogs with contaminated and infected wounds and clinical and laboratory signs of SIRS/sepsis were monitored. The study was approved by the Ethics Committee on Animal Use of the Universidade Estadual de Londrina (CEUA-UEL), recorded under process no. 22863.2011.51.

Clinical cases. The presence of wounds and two or more of the following clinical signs was used as a criterion for SIRS diagnosis: heart rate higher than 150 beats per min, respiratory rate higher than 40 breaths per min, temperature above $39.4^{\circ} \mathrm{C}$ or below $37.2^{\circ} \mathrm{C}$, and leukocyte counts above 19,000 or below $5,000 \mathrm{~mm}^{3}$ (Otto 2007). Lesion duration and macroscopic appearance were used as a criterion to classify the degree of wound contamination; a wound was considered contaminated when presented 6-12 hours after occurrence of injury, and infected when presented for longer than 12 hours of duration with the presence of devitalized tissue and purulent discharge (Dernell 2006).

Epidemiology. Information regarding breed, age, sex, weight, cause of the wound, presence of secondary insult(s), concomitant factor(s), type of injury, quantity of injuries, time elapsed between the occurrence of injury and hospital care, initial treatment(s), and clinical evolution were obtained.

Wound sample collection. Small fragments of the wound(s) were collected for microbiological analysis when the dogs were under general anesthesia for surgical debridement of the wound, after prior antisepsis for $10 \mathrm{~min}$ with chlorhexidine gluconate, followed by washing with sterile physiological solution. In wounds smaller than $5 \mathrm{~cm}$ in diameter, a $6 \mathrm{~mm}$ wide fragment was excised from the center of the wound using a punch biopsy instrument (Kolplast Ltda ${ }^{\circledR}$ ), in wounds between 5 and $10 \mathrm{~cm}$ in diameter, two fragments were collected, and in wounds larger than $10 \mathrm{~cm}$ in diameter, three fragments were collected. The tissues were placed in sterile flasks within isothermic boxes and transported to the Clinical Microbiology Sector of the Clinical Analysis Laboratory of the University Hospital at the State University of Londrina (LAC-HU/UEL) for processing on the same day.

Microbiological analysis. The wound fragments were incubated overnight at $37^{\circ} \mathrm{C}$ in soybean tryptone (SBT) solution and replated on non-selective media including chromogenic, chocolate, and blood agar, and on selective medium such as MacConkey agar, and incubated at $35-37^{\circ} \mathrm{C}$ for $24 \mathrm{~h}$. Then, the Petri dishes were inspected macroscopically and microscopically for bacterial growth, and those that did not exhibit growth were reincubated for a further $24 \mathrm{~h}$. In the positive cultures, the isolated bacteria were manually identified on the basis of colony development on the different culture media, Gram staining, and biochemical/enzymatic tests for microbiological identification according to the method standardized by Versalovic et al. (2011).

For blood cultures, blood was collected from the jugular vein with a syringe and needle, after trichotomy and surgical antisepsis of the ventral cervical region. From small dogs, $5 \mathrm{~mL}$ was collected, while from large ones, $10 \mathrm{~mL}$ was collected. The blood was seeded into commercial flasks for automated culture containing culture medium (BD-Bactec Peds Plus ${ }^{\mathrm{TM}}$ and BD Bactec Plus+Anaerobic) that were placed into a BD Bactec ${ }^{\mathrm{TM}} 9000$ automated blood culture system (BD Diagnostics, Spars, MD, USA), which detects bacterial growth in a period of up to five days. For the flasks that exhibited positive growth, one aliquot of the material seeded onto agar was collected for later identification of the microbial agent and for antibiogram analysis.

In the cases in which correct identification of the microorganism was uncertain, automated identification was performed using VITEK ${ }^{\circledR}$ (bioMérieux-Grenoble, Isère, France) and/or BD Phoenix ${ }^{\mathrm{TM}}$ systems (BD Diagnostics, Spars, MD, USA), which also determined the sensitivity pattern by microdilution.

Antibiotic susceptibility test (AST). Disk diffusion tests were conducted using Muller Hinton agar. A bacterial concentration corresponding to 0.5 turbidity on the McFarland scale was used. The Petri dishes and flasks containing the antibiotic disks were kept at room temperature for 20 to 30 minutes maximum before use. The antibiotic disks were selected on the basis the microbial agents identified in the samples, following the recommen- 
dations of the Clinical and Laboratory Standards Institute (CLSI), and added maximally $15 \mathrm{~min}$ after seeding of the test organisms. A maximum of five disks were used per $100 \mathrm{~mm}$ Petri dish, and the plates were incubated at $35-37^{\circ} \mathrm{C}$. The test was read between 18-24h after incubation. The susceptibility profile was determined by measuring the growth inhibition zone and the results were reported as sensitive, intermediately resistant, or resistant, based on the interpretation of the CLSI breakpoints.

Clinical parameters. Blood was collected from all dogs to obtain a complete blood count. Glucose and lactate blood levels were obtained using Optium Xceed ${ }^{\circledR}\left(\right.$ Abbott $\left.^{\circledR}\right)$ and Accutrend Plus ${ }^{\circledR}$ $\left(\right.$ Roche $^{\circledR}$ ) portable analyzers, respectively. Lactate levels were measured at admission time only and were considered normal when $<2.0 \mathrm{mmol} / \mathrm{L}$, moderately increased when $2.0-4.0 \mathrm{mmol} / \mathrm{L}$, and severely increased when $>4.0 \mathrm{mmol} / \mathrm{L}$. The glycemic index was classified into four categories: hypoglycemic $(<60 \mathrm{mg} / \mathrm{dL})$, normoglycemic $(60-130 \mathrm{mg} / \mathrm{dL})$, moderately hyperglycemic (130$180 \mathrm{mg} / \mathrm{dL})$, and severely hyperglycemic (>180mg/dL).

Mean arterial pressure (MAP) was calculated from three consecutive measurements in one of the forelimbs using the oscillometric method (petMAP ${ }^{\mathrm{TM}}$ graphic). Dogs with a MAP of 65$100 \mathrm{mmHg}$ were considered normotensive dogs, while those with a MAP $<65 \mathrm{mmHg}$ are in a state of hypotension, and those with a MAP $>100 \mathrm{mmHg}$ are hypertensive at the time of evaluation.

Statistical analysis. The statistical package R (R Core Team 2013) was used. The results were analyzed using descriptive statistics (frequencies and percentages, including measures of position and dispersion). Quantitative data were compared by ANOVA. In the cases where the assumptions for ANOVA were not met, the data were transformed (Box \& Cox 1964). Due to the sample size and distribution, the variables with categorical data were evaluated using Fisher's exact test. $\mathrm{P}<0.05$ was considered significant in all cases.

\section{RESULTS AND DISCUSSION}

\section{Epidemiology}

The clinical and laboratory parameters related to the presence or absence of bacteremia evaluated in the 30 dogs with wounds and signs of SIRS/sepsis, and the correlation of these parameters with survival are shown in Table 1 . The overall survival rate was $66.67 \%$. The age of the 30 patients ranged from six months to 16 years (mean age of five years and eight months) and the weight ranged between three and $45 \mathrm{~kg}$ (mean of $14.6 \mathrm{~kg}$ ), and these parameters exerted no effect on patient survival. Twenty (66.66\%) dogs were intact males and 10 were females, of which eight (26.67\%) were non-spayed and two (6.67\%) were spayed. With regard to breeds, 21 (70\%) were mongrel dogs, two (6.67\%) were poodles, and one $(3.33 \%)$ was of each of the following: German Shepherd, Belgian Shepherd, Dachshund, Pit-bull Terrier, Rottweiler, and Dalmatian. Regarding animal care, 18 (60\%) dogs were domiciled, nine (30\%) were semi-domiciled, and three (10\%) were strays dogs. Similar results have been obtained in other studies performed in dogs with traumatic lesions in soft tissues, except that the majority of the individuals had a defined breed (Griffin \& Holt 2001, Buriko et al. 2008, Meyers et al. 2008, Simpson et al. 2009). This may be related to regional factors, as these studies were conducted in areas with different socioeconomic characteristics than that of the present study. In a study of 94 dogs with severe wounds caused by bites from other dogs, Ateca et al. (2015) found an equal proportion of males and females, predominantly mongrel dogs, and $68 \%$ weighed less than $10 \mathrm{~kg}$, because the small dogs suffered more attacks from large dogs.

In the present study, wounds were of unknown etiology in $10(33.33 \%)$ patients, due to biting in nine (30\%), due to being run over in four (13.33\%), and due to each of the following causes in one (3.33\%) dog: burning, cat scratch, reaction to drug application, ulcerated skin nodules, dehiscence of stitches after ovariohysterectomy due to pyometra, mastitis, and decubitus sores. The wounds of unknown etiology were most likely due to bites or being run over, as $40 \%$ of the dogs had free access to the street. In small animals, the largest portion of traumatic wounds is caused by being run over (Dernell 2006, Arias et al. 2008) or by bites (Ateca et al. 2015). According to Pavletic \& Trout (2006), wounds due to biting correspond to $10-15 \%$ of the trauma cases in small animal medicine; however, in the present study, the

Table 1. Clinical and laboratory observations in 30 dogs with wounds and signs of sepsis regarding the presence or absence of bacteremia, correlation of these parameters with survival and mortality $(p)$

\begin{tabular}{|c|c|c|c|c|c|}
\hline \multirow[t]{3}{*}{ Parameters } & \multicolumn{4}{|c|}{ Bacteremia } & \multirow[t]{3}{*}{$P$} \\
\hline & \multicolumn{2}{|c|}{ Yes } & \multicolumn{2}{|c|}{ No } & \\
\hline & Death & Survival & Death & Survival & \\
\hline \multicolumn{6}{|c|}{ Time until receiving care } \\
\hline$\leq 1$ day & 1 & 0 & 1 & 4 & 0.3243 \\
\hline 1-5 days & 2 & 0 & 1 & 8 & \\
\hline$\geq 5$ days & 3 & 1 & 2 & 7 & \\
\hline \multicolumn{6}{|l|}{ Glycemia } \\
\hline$\leq 60$ & 0 & 0 & 2 & 0 & 0.002454 \\
\hline $60-130$ & 2 & 1 & 1 & 17 & \\
\hline $130-180$ & 2 & 0 & 1 & 2 & \\
\hline$\geq 180$ & 2 & 0 & 0 & 0 & \\
\hline \multicolumn{6}{|l|}{ MAP } \\
\hline$\leq 65$ & 0 & 0 & 0 & 1 & 0.2127 \\
\hline $65-100$ & 5 & 0 & 2 & 9 & \\
\hline$\geq 100$ & 1 & 1 & 2 & 9 & \\
\hline \multicolumn{6}{|l|}{ Lactat } \\
\hline$\leq 2$ & 1 & 0 & 1 & 6 & 0.6821 \\
\hline $2-4$ & 2 & 1 & 3 & 9 & \\
\hline$\geq 4$ & 3 & 0 & 0 & 4 & \\
\hline \multicolumn{6}{|l|}{ Wound culture } \\
\hline Gram + & 0 & 0 & 1 & 10 & - \\
\hline Gram - & 3 & 0 & 1 & 8 & \\
\hline 2 Gram + & 1 & 0 & 0 & 0 & \\
\hline 2 Gram - & 1 & 0 & 0 & 0 & \\
\hline 2 Gram +/1Gram - & 0 & 0 & 0 & 1 & \\
\hline 2 Gram -/1Gram + & 0 & 0 & 1 & 0 & \\
\hline 3 Gram + & 0 & 0 & 1 & 0 & \\
\hline 3 Gram - & 0 & 1 & 0 & 0 & \\
\hline \multicolumn{6}{|l|}{ Blood culture } \\
\hline Gram + & 1 & 1 & - & - & 0.0021 \\
\hline Gram - & 5 & 0 & - & - & \\
\hline \multicolumn{6}{|c|}{ Previously administered antibiotics } \\
\hline Cephalosporin & 0 & 0 & 0 & 2 & - \\
\hline $\begin{array}{l}\text { Cephalosporin + } \\
\text { metronidazole }\end{array}$ & 2 & 0 & 1 & 7 & \\
\hline Enrofloxacin & 1 & 0 & 1 & 1 & \\
\hline $\begin{array}{l}\text { Enrofloxacin + } \\
\text { metronidazole }\end{array}$ & 3 & 1 & 1 & 9 & \\
\hline Amoxicillin + & 0 & 0 & 0 & 1 & \\
\hline
\end{tabular}

clavulanic acid 
Table 2. Bacterial isolates from wounds of 30 dogs with signs of sepsis

\begin{tabular}{lcccc}
\hline Gram-positive bacteria & Number of isolates (\%) & Gram-negative bacteria & Number of isolates (\%) & Total \\
\hline Streptococcus spp. & $07(36.84)$ & Pseudomonas aeruginosa & $11(50.00)$ & \\
Enterococcus spp. & $07(36.84)$ & Klebsiella pneumoniae & $06(27.27)$ & \\
Staphylococcus spp. & $05(26.32)$. & Escherichia coli & $03(13.64)$ & \\
& & Proteus spp. & $02(9.09)$ & $41(100)$
\end{tabular}

percentage was doubled (30\%), which can explain the presence of signs of SIRS/sepsis in these animals. Ateca et al. (2015) found that SIRS occurred in 54\% of the patients in dogs with wounds caused by bites. This type of wound has a higher risk of developing clinical complications, as all bite wounds should be considered contaminated because they contain a polymicrobial flora that reflects the aerobic and anaerobic florae of the oral cavity of the bitter, skin of the victim, and environment (Pavletic \& Trout 2006).

The time elapsed between observing the primary insult and receiving care varied between $<1 \mathrm{~h}$ and 11 days, with a mean of 4.88 days after occurrence of the lesion. As a result, both by criteria time as well the appearance of the lesion, wounds were classified as infected in $80 \%(24 / 30)$ of the patients and as contaminated in $20 \%$. Although this factor did not negatively affect patient survival, it is known that the presence of tissue infection may promote sepsis development, as the skin's protective barrier is more vulnerable in case of endothelial disruption, which may promote hematogenous migration of pathogens. Most of authors describes early treatment for dogs with wounds, with no complications in most of patients (Griffin \& Holt 2001, Meyers et al. 2008, Mouro et al. 2010). Ateca et al. (2015) found that the mean duration between wound occurrence and hospitalization was $3 \mathrm{~h}$, and that this factor did not affect mortality and treatment duration, although it did affect the occurrence of positive bacterial cultures, as seen in the present study.

Signs of infection in the wounds and deep-tissue involvement, such as subcutaneous tissue and/or muscle fascia, were observed in all of the patients; lacerated injury was found in $14(46.67 \%)$ cases, abscess was found in six (20\%), penetrating and contused wounds most likely due to bite was found in six (20\%), phlegmon was found in three $(10 \%)$, and second and third-degree burns were found in one $(3.33 \%)$ patient. In multiple animals, we observed secondary insults and/or concomitant systemic alterations, such as dehydration in 19 animals (63.33\%); bone fracture and exposure in six (20\%); gastroenteritis induced by drugs in five (16.67\%); major hemorrhage at the wound site in two $(6.67 \%)$, and each one of the following affections in five $(16.67 \%)$ dogs: urolithiasis, hepatopathy, pneumonia, pneumothorax, and pyothorax. Of the 30 treated dogs, 20 (66.67\%) survived, and 10 (33.33\%) died, and death occurred between 1-20 days after the initial care, with a mean of four days. The degree of deeper tissue involvement and presence of SIRS/sepsis are related to higher mortality rate (Buriko et al. 2008). In dogs with sepsis due to several etiologies, Gebhardt et al. (2009) reported a survival rate of $58 \%$, a value similar to that of the present study. Ateca et al. (2015) found that in dogs with wounds due to bites, the
Table 3. Frequencies of bacterial species isolated from wounds of 30 dogs with signs of sepsis

\begin{tabular}{lc}
\hline Bacteria & Number of Isolates (\%) \\
\hline Pseudomonas aeruginosa & $11(26.83)$ \\
Enterococcus spp. & $7(17.07)$ \\
Klebsiella pneumoniae & $6(14.63)$ \\
Streptococcus pyogenes & $6(14.63)$ \\
Escherichia coli & $3(7.32)$ \\
Staphylococcus pseudointermedius & $3(7.32)$ \\
Staphylococcus aureus & $2(4.88)$ \\
Proteus mirabilis & $1(2.44)$ \\
Proteus vulgaris & $1(2.44)$ \\
Streptococcus milleri & $1(2.44)$ \\
TOTAL & $41(100)$
\end{tabular}

presence of SIRS was directly related to higher mortality, with a rate of $24 \%$, which was lower than that found in the present study.

\section{Microbiological analysis}

Bacteria were isolated from all of the samples collected from the wounds. In total, it was obtained 41 bacterial isolates (Table 2). The frequencies of bacteria in the wounds are shown in Tables 2 and 3. Pseudomonas aeruginosa, Streptococcus spp., and Enterococcus spp. were the most frequently observed. Dryden (2010) stated that Staphylococcus aureus, followed by P. aeruginosa, Escherichia coli, and Enterococcus spp. were the most frequently identified species in skin and soft tissue infections in dogs. Except for the low presence of Staphylococcus aureus in the current study, these findings are in agreement with ours. Meyers et al. (2008) and Mouro et al. (2010) identified Staphylococcus intermedius, Pasteurella multocida, and pyogenic streptococci as the most common agents in wounds due to biting.

Arias et al. (2008, 2011), studying traumatic wounds in dogs, found Pseudomonas spp., Proteus spp. and Staphylococcus spp. as the most frequently isolated bacteria. However, in these two studies, the wounds were sampled using swabs, which frequently identify the contaminant microorganisms on the wound surface, such as Staphylococcus spp. (Pallua et al. 1999). Similarly, Mouro et al. (2010) used swabs to collect sample from wounds during initial presentation, resulting in the isolation of mainly bacteria belonging to the cutaneous flora. The culture from the material collected by biopsy in the present study allowed for identifying bacteria not belonging to the normal skin microbiota, emphasizing the importance of differentiating between pathogens responsible for tissue infection and the skin-colonizing agents, which usually do not require treatment with antimicrobials and do not interfere with the healing duration (Buchanan et al. 1986, Amalsadvala \& Swaim 2006, Meyers et al. 2008, Dryden 2010). 
Table 4. Bacterial isolates from the wounds and blood cultures and evolution of the condition in the seven patients with positive blood culture

\begin{tabular}{cccc}
\hline Patient & Bacterial growth Wound & Bacterial growth Blood & Evolution \\
\hline 02 & Proteus mirabilis & Staphylococcus aureus & death \\
05 & Staphylococcus aureus & Staphylococcus aureus & survival \\
16 & Klebsiella pneumoniae/ & Klebsiella pneumoniae/ & death \\
& Pseudomonas aeruginosa & Escherichia coli/Enterococcus spp. & \\
17 & Pseudomonas aeruginosa & Pseudomonas aeruginosa & death \\
19 & Staphylococcus pseudointermedius/ & Brucella melitensis & death \\
& Streptococcus pyogenes & & death \\
24 & Pseudomonas aeruginosa/ & Acinetobacter baumannii & death
\end{tabular}

Only few veterinary studies on collecting samples from wounds by biopsy have been reported. This technique is considered the gold standard in human medicine for diagnosing infection in skin wounds, because it allows obtaining the bacteria that infect the deeper tissues (Steer 1996, Pallua et al. 1999, Bowler et al. 2001, Amalsadvala \& Swaim 2006, Laitano et al. 2008). In veterinary practice, there is still resistance to applying this technique because it is considered invasive and prone to complications such as hemorrhage (Pallua et al. 1999, Laitano et al. 2008); however, no complications occurred in any of the patients in the present study.

The number of bacterial species in relation to patient is in Table 1. Of the ten dogs that died, three showed polymicrobial infection of the wounds: S. aureus, Proteus vulgaris, and E. coli were isolated from one animal; Streptococcus pyogenes, Enterococcus spp., and S. aureus were isolated from another; and E. coli and Enterococcus spp. were isolated from the third dog. Various types of microorganisms can coexist in the same wound, especially Pseudomonas spp., Streptococcus spp., and Staphylococcus spp. (Amalsadvala \& Swaim 2006). Polymicrobial type of infection is often associated with complications, i.e., bacteremia and/ or endotoxemia (Cowell \& Penwick 1989, Amalsadvala \& Swaim 2006, Dryden 2010), as found in the present study. Any type of wound has the potential to be colonized and/or infected by a wide variety of aerobic and anaerobic microorganisms originating from the environment, the endogenous medium, or skin, and environmental sources frequently predominate in polymicrobial traumatic wounds (Krahwinkel \& Boothe 2006). Enterococcus spp. are present in the soil, water, and endogenous flora of the animals, and can cause infections of the surgical site and wounds in dogs. Although we found Enterococcus spp. at high frequency in the present study, we observed no resistance to vancomycin, which would be a major concern for public health because of possible animal-to-human transmission (Abbot et al. 2008).

Presence of bacteremia (23.33\% of cases) and clinical evolution are in Table 4 . These patients showed a negative clinical evolution, considering that of the seven animals in which bacteremia was confirmed, six died, representing $20 \%$ of the total mortality rate, indicating that bacteremia has a significant effect on mortality. Blood culture is indicated in any seriously ill patient exhibiting fever, leukocytosis with deviation to the left or neutropenia, hypoglycemia, cir- culatory collapse, tachycardia, tachypnea, dyspnea, anuria or oliguria, jaundice, thrombocytopenia, or signs of widespread intravascular clotting (Calvert \& Thomason 2011). Because the dogs with wounds in the present study were intensively monitored to identify signs of SIRS/sepsis, we succeeded in obtaining a number of positive blood cultures. Bacteremia represents a serious clinical complication, with an important role in prognosing sepsis; however, blood cultures are positive in only one third of the cases in human patients with severe sepsis (Hodgin \& Moss 2008). In veterinary medicine, information regarding prevalence of bacteremia in dogs and cats is still quite scarce (Dow et al. 1989, Greiner et al. 2008), but is has been estimated to yield positive results in $30-50 \%$ of blood cultures when performed appropriately (Calvert \& Thomason 2011). Ideally, samples should be collected at three time points (Calvert \& Thomason 2011), which was not performed in the present study, but could increase the percentage of positive blood cultures.

The microbial agents isolated from the blood cultures are in Table 4. The wound and blood cultures contained the same species in two dogs (Table 4). In human patients, before 1987, blood stream infections by gram-negative bacteria were predominant; however, after this period, gram-positive bacteria became the most common agent responsible for the development of severe sepsis (Davies \& Hagen 1997, Otto 2007, Hodgin \& Moss 2008). In veterinary medicine, the predominance of gram-positive or gram-negative bacteria in sepsis remains poorly described (Otto 2007). In blood cultures from dogs with infectious diseases of different origins, S. aureus and Streptococcus spp. are considered the most frequently isolated agents (Greiner et al. 2008), followed by E. coli, although gram-negative microorganisms can be more common in critically ill patients (Calvert \& Thomason 2011), as observed in the present study. E. coli and Pseudomonas spp. are gram-negative microorganisms most commonly cultured in blood cultures of human patients with severe sepsis, and polymicrobial infections are responsible for $5 \%$ of sepsis cases; however, they account for $30 \%$ of cases in patients with severe sepsis (Hodgin \& Moss 2008).

Antibiotics were empirically administered in the initial treatment. In most cases, a combination of drugs, involving broad-spectrum antibiotics such as enrofloxacin and first-generation cephalosporins, such as cephalexin or cephalothin, was used. Enrofloxacin combined with metronidazole 
was used in $43.33 \%$ of cases, followed by first-generation cephalosporins combined with metronidazole (33.33\%), and amoxicillin/clavulanic acid was administered to one (3.33\%) dog. These antibiotics were also used alone, although at a lower frequency (Table 1).

It was not observed the growth of anaerobic bacteria in blood cultures, and this may be occurred as a consequence of metronidazole administration in 24/30 (80\%) patients. However anaerobic culture of the wound material was not performed. Anaerobic microbial growth also did not occur in a low number of cases in which the drug was not used, and although few dogs had not received this drug, it raises the issue whether the use of this antibiotic is really necessary. As metronidazole is metabolized in the liver, critical patients show a trend of developing multiple organ dysfunction, which can contribute to the worsening of clinical status and sepsis (Calvert \& Thomason 2011). Another important point is that anaerobes make up a significant portion of the normal bacterial flora, on most mucosal surfaces, and they play an important role in protection (Greene \& Jang 2011), so it can occur imbalances as a consequence of antibiotic misuse.

\section{AST}

We did not detect any microorganisms exhibiting absolute multiresistence to the antimicrobials tested in vitro. However, among gram-negative bacilli, a high rate of resistance (61.18-95.45\%) to first and third-generation cephalosporins was observed. The bacteria also exhibited high resistance to enrofloxacin (59.1\%), amoxicillin/clavulanic acid $(59.1 \%)$, and sulfa $(72.72 \%)$. Gram-negative bacteria exhibited lower resistance to aminoglycosides such as amikacin $(13.64 \%)$ and gentamicin (27.27\%). Mouro et al. (2010) recommend empirical use of sulfas in dogs with wounds, and in the case of infected wounds, they recommend ampicillin combined with fluoroquinolones, aminoglycosides, or amoxicillin/clavulanic acid. However, these recommendations cannot be simply extrapolated to the location in which the present study was performed, as it is highly advisable to use culturing results and antibiograms to guide the choice of antibiotics (Guardabassi et al. 2010). There was $100 \%$ sensitivity to imipenem and ticarcillin/ clavulanic acid. Nevertheless, its use as well as that of other carbapenems and vancomycin should be discouraged in veterinary medicine because of the possible development of multiresistant bacteria, which pose a risk to humans (Guardabassi et al. 2010). However, these antimicrobials must be tested to obtain information relevant to public health (Mouro et al. 2010).

In the AST of the gram-positive bacteria isolated from the wounds, among the five Staphylococcus spp. isolates, there was higher resistance $(60 \%)$ to clindamycin, gentamicin, sulfamethoxazole/trimethoprim, and tetracycline and $100 \%$ sensitivity to cephalosporins and oxacillin. Streptococcus spp. exhibited the lowest resistance $(0-28.6 \%)$ to the antimicrobials tested and were $100 \%$ sensitive to amoxicillin/clavulanic acid and enrofloxacin. Among the seven Enterococcus spp. isolates, there was $100 \%$ sensitivity to amoxicillin/clavulanic acid, ampicillin, and vancomycin,
$71.4 \%$ resistance to ceftiofur and gentamicin, $42.9 \%$ resistance to erythromycin and tetracycline, and $28.6 \%$ resistance to cephalexin and cefazolin. Because of the high variation in the sensitivity patterns of the agents found, it is impossible to recommend a single antimicrobial or a combination of agents effective against all of the species found in the wounds (Mouro et al. 2010).

The AST results of the microorganisms isolated from the blood cultures were similar to those of the wound cultures, both for gram-positive and gram-negative microorganisms. Among the five gram-negative isolates, $60 \%$ showed resistance to amoxicillin/clavulanic acid, ampicillin, sulfamethoxazole/trimethoprim, and tetracycline, $40 \%$ to cephalexin, cephalothin, cefazolin, and cefoxitin, and 20\% to enrofloxacin and gentamicin, while $100 \%$ displayed sensitivity to amikacin, imipenem, and ticarcillin/clavulanic acid. The two S. aureus samples exhibited $100 \%$ sensitivity to amoxicillin/clavulanic acid, ampicillin, cephalosporins, enrofloxacin, gentamycin, oxacillin, sulfamethoxazole/trimethoprim, tetracycline, and vancomycin, and $50 \%$ resistance to clindamycin, penicillin, and erythromycin. Enterococcus spp. were resistant to erythromycin and gentamycin, and sensitive to amoxicillin/clavulanic acid, ampicillin, cephalosporins, enrofloxacin, tetracycline, and vancomycin.

\section{Clinical and laboratory parameters}

The mean cell volume (MCV) was $21.82 \%$, with hematocrit levels between $8.9 \%$ and $41.6 \%$, but these values were not correlated with mortality. Positive blood culture was not correlated with MCV too. Although anemia is not considered a specific marker of sepsis, these abnormalities may complicate the clinical status of severely ill patients (Johnson et al. 2004).

The admission lactate level ranged from 1.20 to $4.80 \mathrm{mmol} / \mathrm{L}$ with a mean of $3.03 \mathrm{mmol} / \mathrm{L}$, whereas the lactate blood level was normal in eight dogs $(26.37 \%)$, and hyperlactatemia was observed in 22 dogs (73.33\%) (Table 1 ). The lactate level was higher than $3 \mathrm{mmol} / \mathrm{L}$ in $50 \%$ of the dogs that died. However, this parameter was not correlated with higher mortality or occurrence of positive blood culture. The limitation of the present study was that serial measurements of lactate concentration was not performed. The current Surviving Sepsis Campaign guidelines recommend that blood lactate concentration be serially monitored during resuscitation of patients with severe sepsis (Ateca el al. 2015). In human and veterinary medicine, the blood lactate concentration has been used as indirect parameter for evaluating systemic tissue perfusion in critical patients, especially in those exhibiting clinical parameters compatible with SIRS/sepsis, and higher clinical attention should be given to patients with a concentration above $2.0 \mathrm{mmol} / \mathrm{L}$ (Pachtinger \& Drobatz 2008). In some studies, a positive correlation has been found between high lactate values and poor prognosis, mainly in patients with SIRS, severe tissue infections, polytrauma, babesiosis, gastric dilatation-volvulus, and peritonitis (Ateca et al. 2015, Buriko et al. 2008, Butler 2011).

The mean blood glucose concentration in the patients was $120.83 \mathrm{mg} / \mathrm{dL}$, ranging between 22 and $361 \mathrm{mg} /$ 
dL, where 21 (70\%) dogs exhibited normoglycemia, five (16.66\%) were moderately hyperglycemic, two (6.67\%) were severely hyperglycemic, and two (6.67\%) exhibited hypoglycemia. It is estimated that $16 \%$ of dogs exhibit hyperglycemia when severely ill (Torre et al. 2007, Surman \& Fleeman 2013). It was found that glucose level was positively correlated with positive blood cultures $(p=0.0111)$ and death $(\mathrm{p}=0.002454)$. It was observed that in dogs with hypoglycemia $(\leq 60 \mathrm{mg} / \mathrm{dL})$, as well as with severe hyperglycemia $(\geq 180 \mathrm{mg} / \mathrm{dL})$ occurred greater risk of death $(\mathrm{p}=0.002454)$.

Patients with SIRS or sepsis displayed a marked biphasic blood glucose response. Hyperglycemia during the initial phase was attributed to physiological stress and would consequently promote gluconeogenesis. During a more advanced phase, it is common to observe hypoglycemia, which can occur due to a combination of altered glucose production, increased uptake and use of the glucose by tissues, and poor energy input due to anorexia (Le Compte et al. 2013), as most likely occurred in the patients of the present study. In humans, hyperglycemia occurs in more than $90 \%$ of non-diabetic patients in critical condition, and for a long time, this was believed to reflect disease severity. Recently, it was found that hyperglycemia may cause systemic damage, contributing to worsening of prognosis, increased predisposition to infection, increased risk of developing SIRS and sepsis, and that it is associated with increased morbidity and mortality (Torre et al. 2007).

MAP ranged from 61.33 to $190.67 \mathrm{mmHg}$ (mean of 103.33), with $14(46.67 \%)$ animals being normotensive, $12(40 \%)$ being hypertensive, and four being hypotensive $(13.33 \%)$. MAP was not correlated with bacteremia and death, and we noted a MAP above $100 \mathrm{mmHg}$ in $50 \%$ of the 20 surviving dogs (Table 1). This was most likely due to compensatory physiological mechanisms between cardiac output and peripheral vascular resistance that help maintaining adequate tissue perfusion, which can result in adequate MAP despite the hypoperfusion status (Pachtinger \& Drobatz 2008). Hypoperfusion leads to inadequate oxygen delivery to the tissues, and subsequently, to the cells, which can reduce the oxidative metabolism, promoting reduced energy synthesis and imbalance in cellular functions. MAP monitoring is widely used in evaluating cardiovascular function, and although it is not considered a good clinical criterion when used alone to evaluate tissue perfusion (Pachtinger \& Drobatz 2008, Butler et al. 2011), in combination with other clinical and laboratory parameters, it helps in early identification of seriously ill patients (Pachtinger \& Brobatz 2008), as corroborated by this study. Critical patients should be sequentially tested for several clinical and laboratory parameters to evaluate the therapeutic efficacy (Gebhardt et al. 2009).

Infections of the skin and soft tissues are one of the most common reasons for consultation in small animal clinical routine. The degree of severity and extent of the wounds is highly variable, and can be only superficial and without complications or extensive and with secondary consequences. The primary insult can generate an intense inflammatory response, SIRS and then sepsis, requiring early recog- nition for instituting intensive care. In traumatized animals with wounds, early recognition of the systemic signs compatible with SIRS and identification of the bacteria present is essential to avoid perpetuation of the systemic changes, which may increase the hospital cost and increase the mortality rate, especially in critical patients.

\section{CONCLUSIONS}

We conclude that the technique of collecting material from the wounds by punch biopsy for subsequent culture and antibiogram analysis is safe and efficacious. We identified mainly Pseudomonas aeruginosa, Klebsiella pneumoniae, and Enterococcus spp.; bacteria that do not belong to the normal skin microbiota. It is important to correctly identify the microbial agents involved in wound infection to avoid indiscriminate or incorrect use of antibiotics, as might occurs when skin swab culture is used, when growth of skin-surface bacteria could occur.

Among the gram-negative bacteria isolated from the wounds of the 30 dogs, there was a high incidence of resistance to several classes of antibiotics such as cephalosporins and sulfas, and intermediate resistance to enrofloxacin and amoxicillin/clavulanic acid. The class of aminoglycosides such as amikacin and gentamycin comprised the antimicrobials with the lowest resistance among gram-negative bacteria. We observed no resistance to imipenem and ticarcillin/clavulanic acid, important antibiotics in human medicine that should be avoided in veterinary medicine. Enrofloxacin and amoxicillin/clavulanic acid were the antibiotics with the lowest resistance among gram-positive bacteria. However, it is not possible to recommend a single effective antibiotic due to the high variation in antibiotic sensitivity observed among the different bacterial species isolated, where culturing and AST are advisable in patients with wounds and signs of SIRS/sepsis.

In blood cultures, gram-negative bacteria were predominant, which negatively affected the patient survival. Within this bacterial class, there was higher resistance to amoxicillin/clavulanic acid, ampicillin, sulfas, and tetracycline, and sensitivity to amikacin.

The presence of hypoglycemia or hyperglycemia negatively affected patient survival, highlighting the importance of measuring blood glucose levels in dogs with SIRS/sepsis due to contaminated and infected wounds.

\section{REFERENCES}

Abbott Y., Kirby B.M., Karczmarczyk M., Markey B.K., Leonard F.C. \& Fitzgerald S. 2009. High-level gentamicin-resistant and vancomycin-resistant Enterococcus faecium isolated from a wound in a dog. J. Small Anim. Pract. 50:194-197.

Amalsadvala T. \& Swaim S. 2006. Management of hard to heal wound. Vet. Clin. N. Am., Small Anim. Pract. 36:693-711.

Arias M.V.B., Ishii J.B. \& Freitas J.C. 2011. Resistência de bactérias isoladas de cães e gatos no Hospital Veterinário da Universidade Estadual de Londrina (2008-2009). Pesq. Vet. Bras. 31(6):533-537.

Arias M.V.B., Bataglia L.A., Aiello G., Carvalho T.T. \& Freitas J.C. 2008. Identificação da suscetibilidade antimicrobiana de bactérias isoladas de cães e gatos com feridas traumáticas contaminadas e infectadas. Semina, Ciênc. Agrárias 29(4):861-874.

Ateca L.B., Dombrowski S.S. \& Silverstein D.C. 2015. Survival analysis of 
critically ill dogs with hypotension with or without hyperlactatemia: 67 cases (2006-2011). J. Am. Vet. Med. Assoc. 246(1):100-104.

Box G.E.P. \& Cox D.R. 1964. An analysis of transformations. J. Royal Statist. Soc. 26:211-252.

Bowler P.G., Duerden B.I. \& Armstrong D.G. 2001. Wound microbiology and associated approaches to wound management. Clin. Microbiol. Rev. 14(2):244-69.

Brainard B.M. \& Brown A.J. 2011. Defects in coagulation encountered in small animal critical care. Vet. Clin. N. Am., Small Anim. Pract. 41:783803.

Buchanan K., Heimbach D.M., Minshew B.H. \& Coyle M.B. 1986. Comparison of quantitative and semi quantitative culture techniques for burn biopsy. J. Clin. Microbiol. 23(2):258-261.

Buriko Y., Van Winkle T.J., Drobatz K.J., Rankin S.C. \& Syring R.S. 2008. Severe soft infections in dogs: 47 cases (1996-2006). J. Vet. Emerg. Crit. Care 18(6):608-618.

Butler A.L. 2011. Goal-directed therapy in small animal critical illness. Vet. Clin. N. Am., Small Anim. Pract. 41:817-838.

Calvert C.A. \& Thomason J.D.2011. Cardiovascular infections, p.912-932. In: Greene C.E. (Ed.), Infectious Diseases of the Dog and Cat. 4th ed. Elsevier, St Louis. 1354p.

CLSI 2008. Performance Standards for Antimicrobial Disk and Dilution Susceptibility Tests for Bacteria Isolated from Animals: Approved Standard. 3rd ed. Clinical and Laboratory Standards Institute, Wayne, Pennsylvania, 28(8):2-11.

Cowell A.K. \& Penwick R.C. 1989. Dog bite wounds: a study of 93 cases. Comp. Cont. Educ. Pract. Vet. 11(3):313-318.

Davies M.G. \& Hagen P.O. 1997. Systemic inflammatory response syndrome. Brit. J. Surg. 84:920-935.

Dernell W.S. 2006. Initial wound management. Vet. Clin. N. Am., Small Anim. Pract. 36(4):713-738.

Dow S.W., Curtis C.R. \& Jones R.L. 1989. Bacterial culture of blood from critically ill dogs and cats: 100 cases (1985-1987). J. Am. Vet. Med. Assoc. 195(1):113-117.

Dryden M.S. 2010. Complicated skin and soft tissue infection. J. Antimicrob. Chemother. 65(3):35-44.

Gebhardt C., Hirschberger J., Rau S., Arndt G., Krainer K., Schweigert F.J., Brunnberg L., Kaspers B. \& Kohn B. 2009. Use of C-reactive protein to predict outcome in dogs with systemic inflammatory response syndrome or sepsis. J. Vet. Emerg. Crit. Care 19(5):450-458.

Greiner M., Wolf G. \& Hartmann K. 2008. A retrospective study of the clinical presentation of 140 dogs and 39 cats with bacteraemia. J. Small Anim. Pract. 49:378-383.

Greene C.E. \& Jang S.S. 2011. Anaerobic infections, p.411-416. In: Greene C.E. (Ed.), Infectious Diseases of the Dog and Cat. 4th ed. Elsevier, St Louis. $1354 \mathrm{p}$.

Griffin G.M. \& Holt D.E. 2001. Dog-bite wounds: bacteriology and treatment outcome in 37 cases. J. Am. Anim. Hosp. Assoc. 37:453-460.
Guardabassi L., Jensen L.B. \& Kruse H. 2010. Guia de Antimicrobianos em Veterinária. Artmed, Porto Alegre. 267p.

Hedlund C.H. 2007. Surgery of the integumentary system, p.161-259. In: Fossum T.W. (Ed.), Small Animal Surgery. 3rd ed. Mosby Elsevier, Missouri.

Hodgin K.E. \& Moss M. 2008. The epidemiology of sepsis. Curr. Pharm. Design 14:1833-1839.

Johnson V., Gaynor A., Cha D.L. \& Rozanski E. 2004. Multiple organ dysfunction syndrome in humans and dogs. J. Vet. Emerg. Crit. Care 14(3):158166.

Krahwinkel D.J. \& Boothe H.W. 2006. Topical and systemic medications for wounds. Vet. Clin. N. Am., Small Anim. Pract. 36(4):739-757.

Laitano F.F., Arnt R.A., Cosner A.M. \& Doncato L.F. 2008. Estudo comparativo entre o exame da biópsia e do "swab" cutâneo para o diagnóstico de infecção em pacientes queimados do HPS, Porto Alegre. Revta Bras. Cir. Plást. 23(3):162-166.

Le Compte A.J., Pretty C.G., Lin J., Schaw G.M., Lynn A. \& Chase J.G. 2013. Impact of variation in patient response on model-based control of glycaemia in critically ill patients. Comput. Methods Programs Biomed. 109:211-219.

Meyers B., Schoeman J.P., Goddard A. \& Picard J. 2008. The bacteriology and antimicrobial susceptibility of infected and non-infected dog bite wounds: fifty cases. Vet. Microbiol. 127:360-368.

Mouro S., Vilela C.L. \& Niza M.M.R.E. 2010. Clinical and bacteriological assessment of dog-to-dog bite wounds. Vet. Microbiol. 144:127-132.

Otto C.M. 2007. Sepsis in veterinary patients: what do we know and where can we go? J. Vet. Emerg. Crit. Care 17(4):329-332.

Pachtinger G.E. \& Drobatz K. 2008. Assessment and treatment of hypovolemic states. Vet. Clin. N. Am., Small Anim. Pract. 38:629-643.

Pallua N., Fuchs P.C., Hafemann B., Völpel U., Noah M. \& Lütticken R. 1999. A new technique for quantitative bacterial assessment on burn wounds by modified dermabrasion J. Hosp. Infect. 42(4):329-337.

Pavletic M.M. \& Trout N.J. 2006. Bullet, bite and burn wounds in dogs and cats. Vet. Clin. N. Am., Small Anim. Pract. 36(4):873-93.

R Core Team. 2013. R: a language and environment for statistical computing. R Foundation for Statistical Computing, Vienna, Austria. URL <http://www.R-project.org/>

Simpson S.A., Syring R.S. \& Otto C.M. 2009. Severe blunt trauma in dogs: 235 cases (1997-2003). J. Vet. Emerg. Crit. Care 19(6):588-602.

Steer J.A. 1996. Quantitative microbiology in the management of burn patients. I. Correlation between quantitative and qualitative burn wound biopsy culture and surface alginate swab culture. Burns 22(3): 173-176.

Surman S. \& Fleeman L. 2013. Continuous glucose monitoring in small animals. Vet. Clin. N. Am., Small Anim. Pract. 43:381-406.

Torre D.M., De Laforcade A.M. \& Chan D.L. 2007. Incidence and clinical relevance of hyperglycemia in critically ill dogs. J. Vet. Intern. Med. 21:971-975.

Versalovic J., Carriol K., Funke G., Jorgensen J.H., Landry M. \& Warnock D.W. 2011. Manual of Clinical Microbiology. 10th ed. ASM Press. 2552p. 